\title{
Uma nova abordagem para a modelagem das relações entre os determinantes da satisfação dos clientes de serviços
}

\author{
Maria Auxiliadora Cannarozzo Tinoco \\ José Luis Duarte Ribeiro \\ UFRGS
}

\begin{abstract}
Resumo
Este artigo apresenta uma nova abordagem para a modelagem das relações entre os determinantes da satisfação dos clientes de serviços. As principais vantagens da abordagem proposta em relação aos métodos tradicionais de modelagem, como, por exemplo, as equações estruturais, são: (i) possibilidade de identificar as relações entre múltiplos determinantes utilizando um tamanho de amostra relativamente pequeno, (ii) utilização de um procedimento estatístico mais simples, (iiii) possibilidade de minimizar o erro de especificação no processo de modelagem, visto que podem ser consideradas todas as variáveis relevantes sem tornar o modelo muito complexo. A abordagem proposta é ilustrada através de um estudo aplicado a clientes de restaurantes à la carte. Esse estudo possibilitou construir diagramas de enlaces causais, validar a modelagem proposta e identificar aspectos que convergem e divergem com resultados previamente apresentados na literatura.
\end{abstract}

Palavras-chave

Modelagem, determinantes da satisfação dos clientes, serviços.

\section{A new approach for modeling client satisfaction determinants relationships in services}

\begin{abstract}
This article presents a new approach for modeling client satisfaction determinants relationships in service environment. The principal advantages between proposed approach and traditional methods for modeling relationships, like, for example, structural equation modeling, are: (i) possibility of identifying relationships between multiple determinants by using a relatively small sample size, (ii] request a simpler statistical estimation procedure, (iii) possibility of minimizing the specification error on modeling process, since it can be considered all significant variables without getting a very complex model. The proposed approach is showed by an applied study with a la carte restaurant clients. This study made possible construct causal diagrams, validity the proposed modeling and identifying converging and diverging aspects from literature findings.
\end{abstract}

Key words

Modeling, client satisfaction determinants, services. 


\section{INTRODUĈ̣̃O}

As mudanças ocorridas nas últimas décadas no cenário econômico mundial representam uma das causas principais das novas medidas de desempenho econômico para empresas, indústrias e setores econômicos nacionais. Na economia atual, a avaliação convencional de produtividade já não é representativa do crescimento econômico, portanto, produzir mais, embora eficientemente, não é necessariamente melhor (FORNELL et al., 1996).

Outra das conseqüências das transformações que a economia mundial vem experimentando é o crescimento da indústria de serviços. O setor de serviços vem ganhando importância crescente em muitos países e seu crescimento pode ser visto pelo aumento não só em volume, mas na variedade e diversidade de benefícios intangíveis que são oferecidos aos consumidores. As novas tecnologias são responsáveis pelas mudanças na natureza de muitos serviços existentes e pela criação de novos tipos de serviços (BATESON; HOFFMAN, 2001).

Neste contexto de mercados competitivos e diversificados, onde o setor de serviços vem ocupando uma posição de destaque na economia mundial, as empresas têm procurado estabelecer políticas estratégicas direcionadas para o consumidor e para o mercado, no intuito de conquistar e manter clientes e garantir a sua sobrevivência.

Hoje em dia, as empresas reconhecem que podem competir de modo mais eficaz distinguindo-se pela qualidade dos serviços e maior satisfação de seus consumidores. A satisfação do cliente em relação a um produto ou serviço é influenciada de modo significativo pela avaliação que o consumidor faz de suas características (ZEITHAML, 2003). Diante deste cenário, é fundamental para as empresas de serviços aproximarem-se do cliente, conhecer suas necessidades, expectativas e identificar os atributos mais importantes do serviço oferecido (SARAVANAN; RAO, 2007). Segundo Zeithaml (2003), as empresas descobriram que o aumento dos níveis de satisfação pode ser associado à lealdade dos clientes e aos lucros. Consumidores satisfeitos podem repetir a compra do produto ou serviço, o que traz benefícios à empresa e a torna mais competitiva. Isto foi constatado por Morgan e Rego (2006) ao estudarem o impacto da satisfação dos clientes nos indicadores de desempenho de importantes empresas norte-americanas. Por outro lado, a satisfação do cliente pode ser utilizada como um indicador relevante da saúde da economia de um país, através da avaliação da qualidade de tudo que é produzido e consumido em nível nacional. Essa avaliação é considerada tão importante quanto um indicador de qualidade de vida (FORNELL et al., 1996, p. 12).

O impacto da satisfação do cliente sobre o desempenho das empresas e das economias nacionais tem sido estudado por muitos pesquisadores, e têm surgido diversos modelos que relacionam as atitudes e comportamentos dos clientes com a satisfação. Expectativas prévias, qualidade percebida, desejos pessoais, emoções, desconfirmação de expectativas, preço, valor e imagem, constituem os principais fatores envolvidos no processo de satisfação dos clientes e, desta forma, são denominados comumente de determinantes ou antecedentes da satisfação.

\section{iante deste cenário, é fundamental para as empresas de serviços aproximarem-} cliente, conhecer suas necessidades, expectativas e identificar os atributos mais
importantes do serviço oferecido.

Uma das técnicas para a identificação das relações existentes entre os determinantes da satisfação e a construção dos modelos causais é a modelagem através de equações estruturais. Contudo, esta técnica tem sido muito pouco utilizada em pesquisas no Brasil, devido à complexidade dos cálculos e ao requerimento de uma amostra relativamente extensa para avaliar os determinantes envolvidos. Neste contexto, surge a necessidade de uma metodologia mais simples para a construção de modelos causais de satisfação do cliente, onde possam ser avaliadas as relações de múltiplas variáveis utilizando tamanhos de amostra menores. O presente artigo vem apresentar uma nova abordagem para a modelagem das relações entre os determinantes da satisfação dos clientes de serviços, ilustrada através de uma aplicação prática do serviço oferecido pelos restaurantes à la carte.

\section{REFERENCIAL TEÓRICO}

\section{Satisfação do cliente}

A satisfação do cliente pode ser definida como um estado afetivo gerado pela reação emocional à experiência com um produto ou serviço (CADOTTE et al., 1987; OLIVER, 1980). Esta satisfação também pode ser entendida como a avaliação feita pelo cliente com respeito a um produto ou serviço, em relação ao atendimento ou não das necessidades e expectativas do próprio cliente. A falha em ir ao encontro das necessidades e expectativas 
dos clientes é pressuposta como causadora da insatisfação (ZEITHAML, 2003).

As definições anteriores correspondem à satisfação do cliente com uma transação específica. No entanto, existe outro conceito de satisfação que abrange um processo cumulativo. A satisfação acumulada é uma avaliação global baseada na compra e experiência de consumo com um bem ou serviço com o passar do tempo (ANDERSON et al., 1994). Para Wang e Lo (2002), esta última definição é mais útil na previsão do comportamento dos consumidores e do desempenho da empresa.

Bateson e Hoffman (2001) indicam três razões fundamentais para justificar a satisfação do cliente:

1. Custo de novos clientes versus clientes antigos: mudanças no mercado estão contribuindo para que obter novos clientes se torne mais caro do que manter clientes antigos. Não há tantos novos clientes como costumava haver, e os clientes existentes estão gastando menos. Outros motivos da importância de manter clientes são o aumento acirrado da concorrência e o custo de marketing e propaganda para atrair novos clientes. Portanto, considerando que as empresas gastam muito mais para obter novos clientes, elas devem estabelecer estratégias que visem à satisfação de seus clientes antigos.

2. Demanda competitiva por satisfação: devido ao crescimento da concorrência dos mercados e ao surgimento de novas escolhas para os clientes, aumenta a importância de sua satisfação para as empresas que buscam incrementar os níveis de retenção ou lealdade dos consumidores e, em conseqüência, os lucros.

3. Valor do ciclo de vida dos clientes: a retenção de clientes para uma empresa pode aumentar a lucratividade em função de sua permanência, considerando o alto custo de obter esses consumidores e os custos administrativos para manter cadastros, bancos de dados e afins. À medida que permanecem com a empresa, diminuem estes custos e tornam-se cada vez mais lucrativos.

Em relação à avaliação da satisfação do cliente de serviços, Bitran e Lojo (apud EVRARD; RODRIGUES, 1995, p. 2) ressaltam que a natureza intangível dos serviços torna complexa a avaliação geral de suas características e especificações porque os benefícios psicológicos oferecidos não são facilmente observáveis e ainda menos mensuráveis.

\section{Determinantes da satisfação do cliente}

Os determinantes representam as possíveis variáveis que afetam a avaliação do produto ou serviço feita pelo cliente. Os modelos de satisfação do cliente encontrados na literatura são muito diversos. A seguir, apresentam-se os principais determinantes da satisfação do cliente que estruturam os modelos pesquisados.

\section{- Expectativas}

Olson e Dover (apud SPRENG et al., 1996) indicam que as expectativas são as crenças sobre os atributos ou desempenho de um produto em qualquer momento no futuro. Segundo Fornell et al. (1996), as expectativas representam as experiências de consumo anteriores - incluindo as adquiridas através de propaganda boca-a-boca - e a previsão da capacidade do fornecedor para proporcionar produtos de qualidade no futuro.

\section{- Desempenho percebido}

O desempenho percebido é definido por alguns autores como o nível de qualidade percebida de um produto ou serviço em relação ao preço pago (JOHNSON et al., 1995; JOHNSON et al., 1996). Para estes autores, o desempenho percebido possui o mesmo sentido do valor percebido pelo cliente.

\section{- Desconfirmação de expectativas}

A desconfirmação é produzida pela discrepância entre as expectativas anteriores e o desempenho real do produto percebido pelo cliente (CHURCHILL; SURPRENANT, 1982). Quando o desempenho percebido é igual às expectativas, tem-se uma confirmação, geradora de indiferença, quando é superior às expectativas, existe uma desconfirmação positiva ou afirmação, geradora de satisfação, e, quando é inferior, ocorre uma desconfirmação negativa geradora de insatisfação (NASCIMENTO, 1998).

\section{- Qualidade percebida}

Fornell et al. (1996) definem a qualidade percebida como a avaliação em nível de mercado de uma experiência recente de consumo. Segundo estes autores a qualidade percebida pode ser chamada também de desempenho percebido. Conforme outros autores, a qualidade percebida pode ser definida como os julgamentos do consumidor sobre a excelência ou superioridade global do produto (ANDERSON et al., 1994; BEI; CHIAO, 2001).

\section{- Valor percebido}

O valor é definido como o nível percebido da qualidade do produto em relação ao preço pago (FORNELL et al., 1996). Segundo Andreassen e Lindestad (1998), valor é uma variável agregada que reflete a percepção de todos os atributos da qualidade como uma função do preço.

\section{- Preço}

Bei e Chiao (2001) definem o preço (do ponto de vista do consumidor) como aquilo ao qual se renuncia ou que é sacrificado na obtenção de um produto. Quando o cliente percebe que o preço de um produto ou serviço é razoável, ele se sentirá mais satisfeito e manifestará intenções de 
repetir a compra. Por outro lado, se o consumidor sente que seu sacrifício não vale a pena, ele poderá não repetir a compra, mesmo que esteja satisfeito com a qualidade do produto ou serviço. Além disso, a relação inversa da satisfação do consumidor sobre o preço também pode ser constatada, na medida em que um aumento na satisfação diminui o impacto negativo de um aumento no preço (HOMBURG et al., 2005).

\section{- Desejos}

Conforme Spreng et al. (1996), os desejos são os níveis de atributos ou benefícios que o consumidor almeja alcançar com a aquisição de um produto e que estão associados com a mais alta escala de valores. Do ponto de vista de Sheth et al. (2001), um desejo é o afã de obter mais satisfação do que é realmente necessário e ocorre quando as pessoas querem levar suas condições físicas e psicológicas a um nível além do estado de conforto mínimo.

\section{- Afetos / Emoções}

Os afetos são definidos como o somatório de experiências positivas e negativas respectivamente com um produto ou serviço (OLIVER, 1993). Sheth et al. (2001) definem as emoções como a consciência da ocorrência de alguma excitação fisiológica seguida por uma resposta comportamental e uma avaliação cognitiva. Essas emoções orientam as ações do dia a dia das pessoas e são geradas através de estímulos que podem vir do ambiente externo e também de dentro do organismo (fome, dor de cabeça).

\section{- Imagem corporativa}

Keller (apud ANDREASSEN; LINDESTAD, 1998) define a imagem corporativa como as percepções sobre uma organização que são fixadas na memória do consumidor. A conduta ética de uma empresa pode ter um impacto significativo sobre as percepções que o público tem dela e sobre as decisões de ser ou não cliente seu. Em muitos casos, a imagem corporativa relaciona-se não com o produto principal oferecido, mas com alguma outra ação que desempenha (SHETH et al., 2001).

\section{Modelos de satisfação do consumidor}

\section{- Modelo de desconfirmação de expectativas}

Grande parte das pesquisas encontradas na literatura sobre satisfação está focada na desconfirmação de expectativas como principal determinante da satisfação do cliente. Oliver (1980) foi um dos primeiros autores a incluir a desconfirmação de expectativas no modelo de satisfação do cliente. Conforme o autor, sentimentos de satisfação são alcançados quando os consumidores comparam suas percepções de desempenho do produto com suas expectativas. Se o desempenho percebido exceder as expectativas do consumidor (desconfirmação positiva), o cliente estará satisfeito. Contudo, se o desempenho percebido for menor do que as expectativas (desconfirmação negativa), o cliente estará insatisfeito. A Figura 1 apresenta o modelo de desconfirmação de expectativas proposto por Oliver (1980).

Figura 1: Modelo cognitivo dos antecedentes e conseqüências da satisfação.

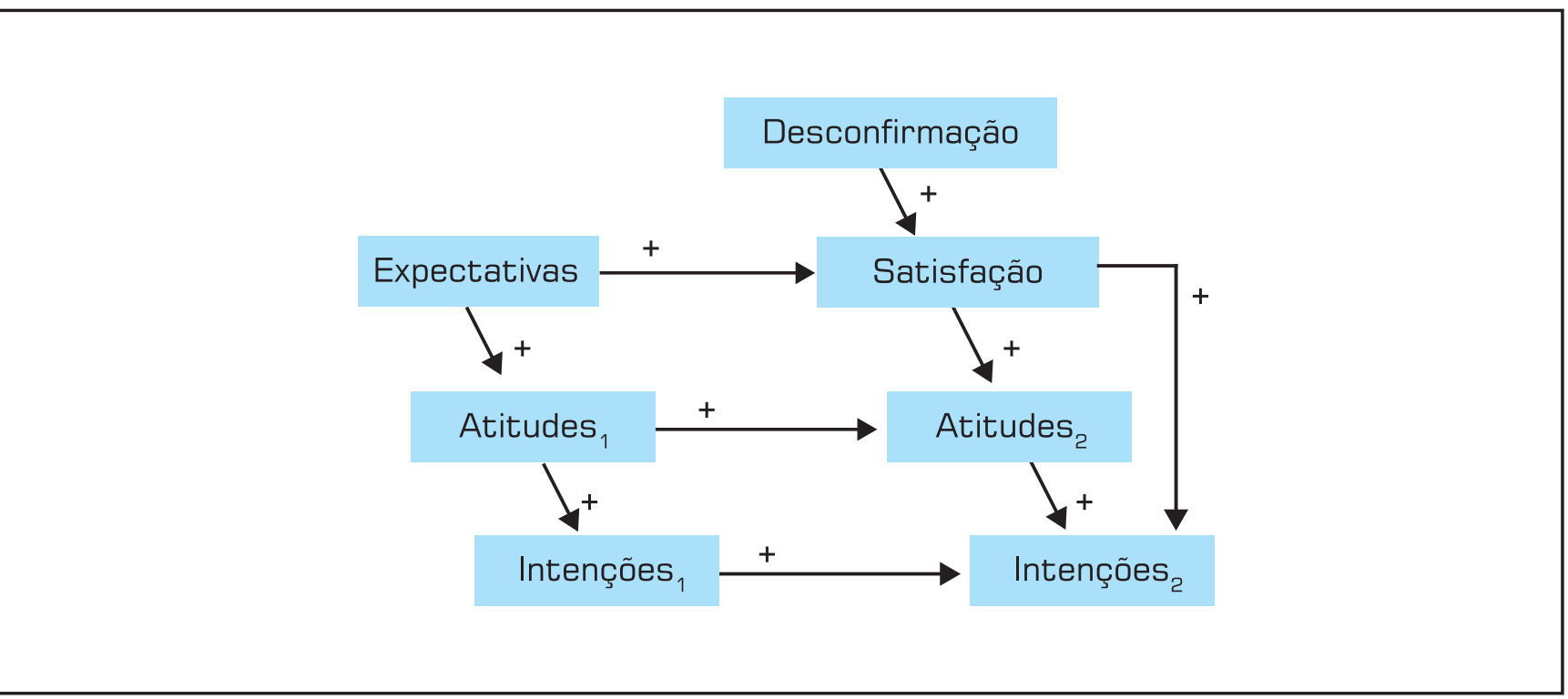

Fonte: Adaptado de Oliver (1980). 
Outros pesquisadores (eg. CHURCHILL; SURPRENANT, 1982; BEARDEN; TEEL, 1983; CADOTTE et al., 1987; TSE; WILTON, 1988; TSIROS et al., 2004) avaliaram o modelo de desconfirmação de expectativas proposto por Oliver (1980) com outros tipos de produtos e serviços, obtendo algumas diferenças em relação à influência direta das expectativas e do desempenho percebido sobre a satisfação do consumidor. Estas diferenças podem ser explicadas principalmente pela natureza dos diversos contextos avaliados.

são medidas junto com as percepções de desempenho (depois do uso do produto ou serviço), elas podem ser utilizadas para estimar a satisfação dos clientes e vice-versa.

\section{- Inclusão dos afetos no modelo de desconfirmação de expectativas}

As bases afetivas da satisfação não estão bem representadas nas perspectivas cognitivas descritas anteriormente. Segundo Oliver (1993), o papel dos eventos como agente causal de estados afetivos positivos e negativos não tem sido suficientemente estudado na literatura. Diversos tipos de experiências do dia-a-dia podem gerar nas pessoas diferentes tipos de afetos. Em vista desta necessidade, ele incorpora os paradigmas afetivos (positivo e negativo) ao modelo de desconfirmação de expectativas como determinantes da satisfação dos clientes. O modelo

Com o objetivo de esclarecer o papel destes determinantes sobre a satisfação, Yi (1993) identificou as condições nas quais os efeitos das expectativas, desconfirmação e desempenho sobre a satisfação são significativos ou não. Especificamente, sua proposta é baseada na ambigüidade do produto como moderador do processo de formação da satisfação do consumidor. O autor sugere que, quando os produtos são ambíguos (qualidade difícil de avaliar), a satisfação dos consumidores é determinada principalmente por suas expectativas prévias. Se não existe uma forma objetiva de julgar um produto, os consumidores utilizam critérios subjetivos baseados nas suas expectativas anteriores. Por outro lado, quando os produtos não são ambíguos ou fáceis de avaliar, eles podem ser julgados objetivamente e as percepções do consumidor sobre o desempenho do produto são formadas com convicção. Nesses casos, a satisfação será determinada fundamentalmente pelo desempenho percebido do produto.

Por outro lado, Johnson et al. (1996) examinaram a natureza das expectativas dos clientes, percepções de desempenho e satisfação para os serviços de empréstimos de banco. Conforme esses autores, o empréstimo dos bancos representa um serviço complexo e relativamente intangível em que os consumidores possuem pouca ou nenhuma experiência. $\mathrm{O}$ modelo proposto sugere que o principal determinante da satisfação do cliente é o desempenho percebido. A carência de expectativas suficientemente formalizadas no serviço de empréstimos de bancos determina a pouca influência das expectativas sobre a satisfação. Ainda em relação a esse assunto, Appleton-Knapp e Krentler (2006) encontraram que a influência das expectativas sobre a satisfação depende do método utilizado para medir as expectativas dos clientes. Quando as expectativas proposto por Oliver (1993) é apresentado na Figura 2.

As satisfações e insatisfações de atributos são resultantes das observações do desempenho do produto desde o ponto de vista do consumidor. O modelo expandido de Oliver (1993) sugere que essas satisfações e insatisfações de atributos afetam diretamente a satisfação dos clientes, assim como os afetos positivos e negativos e a desconfirmação de expectativas.

Jun et al. (2001) estenderam os estudos de Oliver (1993) sobre o papel da experiência afetiva na satisfação do cliente. Eles propõem que o afeto tem uma maior influência na satisfação quando a discrepância entre o desempenho percebido e as expectativas é negativa do que quando é positiva. Assim, quando a discrepância é negativa, o afeto passa a ser o determinante principal da satisfação. Desta forma, os julgamentos de insatisfação estão dominados pela experiência afetiva em lugar da avaliação cognitiva.

\section{- Inclusão de desejos no modelo de desconfirmação de expectativas}

Spreng et al. (1996) consideram importante na formação dos sentimentos de satisfação do cliente o grau no qual um produto ou serviço realiza os desejos do consumidor. O modelo proposto por estes autores contempla que a satisfação global do cliente com um produto ou serviço é influenciada diretamente pela satisfação do consumidor com o produto ou serviço em si (satisfação por atributo) e pela satisfação com a informação usada na escolha do produto (satisfação por informação). As satisfações por atributo e por informação são produzidas pela percepção do consumidor do grau no qual o desempenho do produto ou serviço alcança ou excede seus 
desejos (congruência de desejos) e expectativas (congruência de expectativas), como se observa na Figura 3.

Olshavsky e Kumar (2001) continuaram as pesquisas de Spreng et al. (1996) e concluíram que o modelo que con- sidera os desejos como determinante da satisfação com os bens e as expectativas como determinante da satisfação com a informação, oferece a melhor base para prever a satisfação global do cliente.

Figura 2: Inclusão dos afetos no modelo de desconfirmação de expectativas.

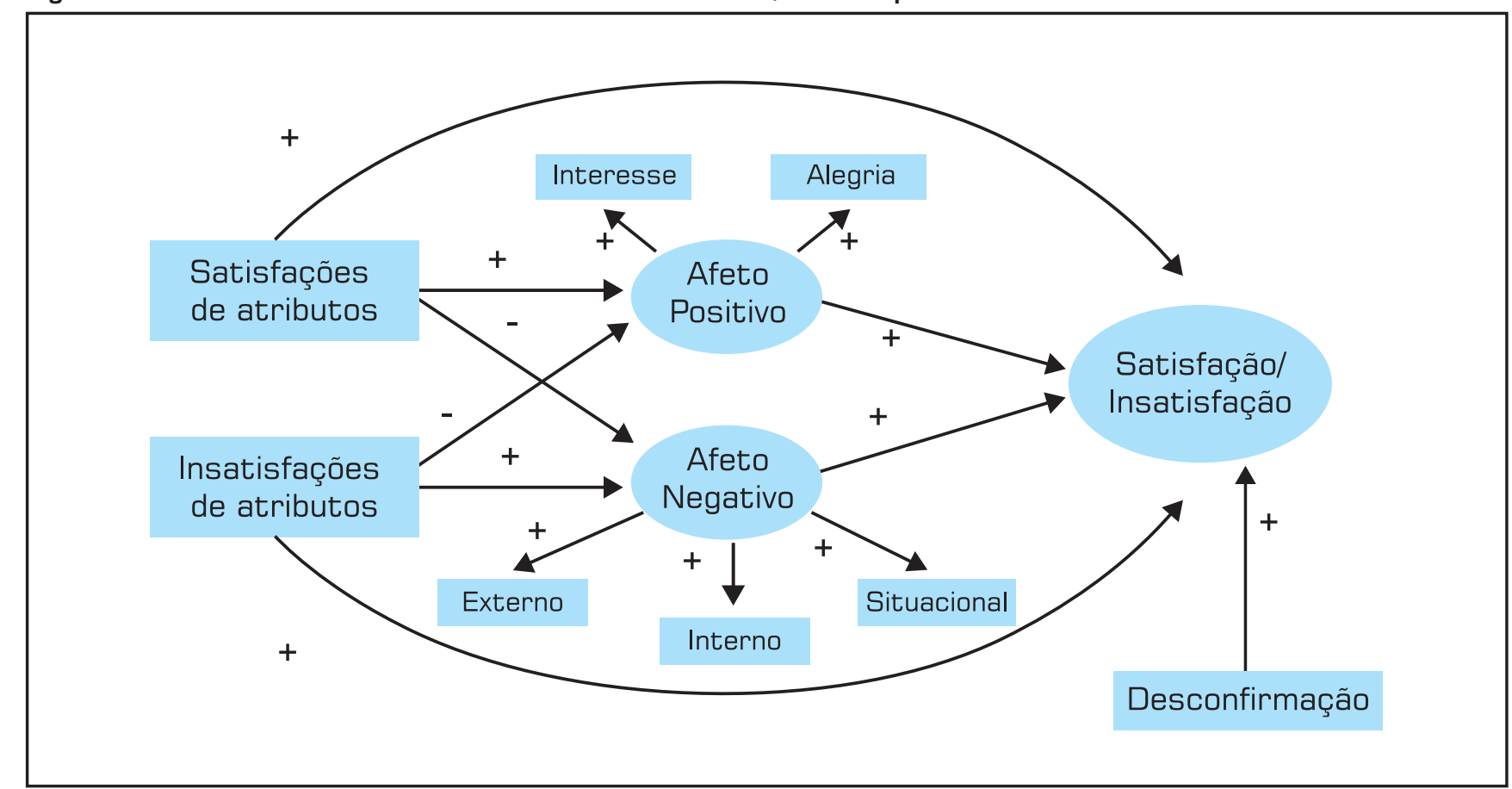

Fonte: Adaptado de Oliver (1993).

Figura 3: Inclusão dos desejos no modelo de desconfirmação de expectativas.

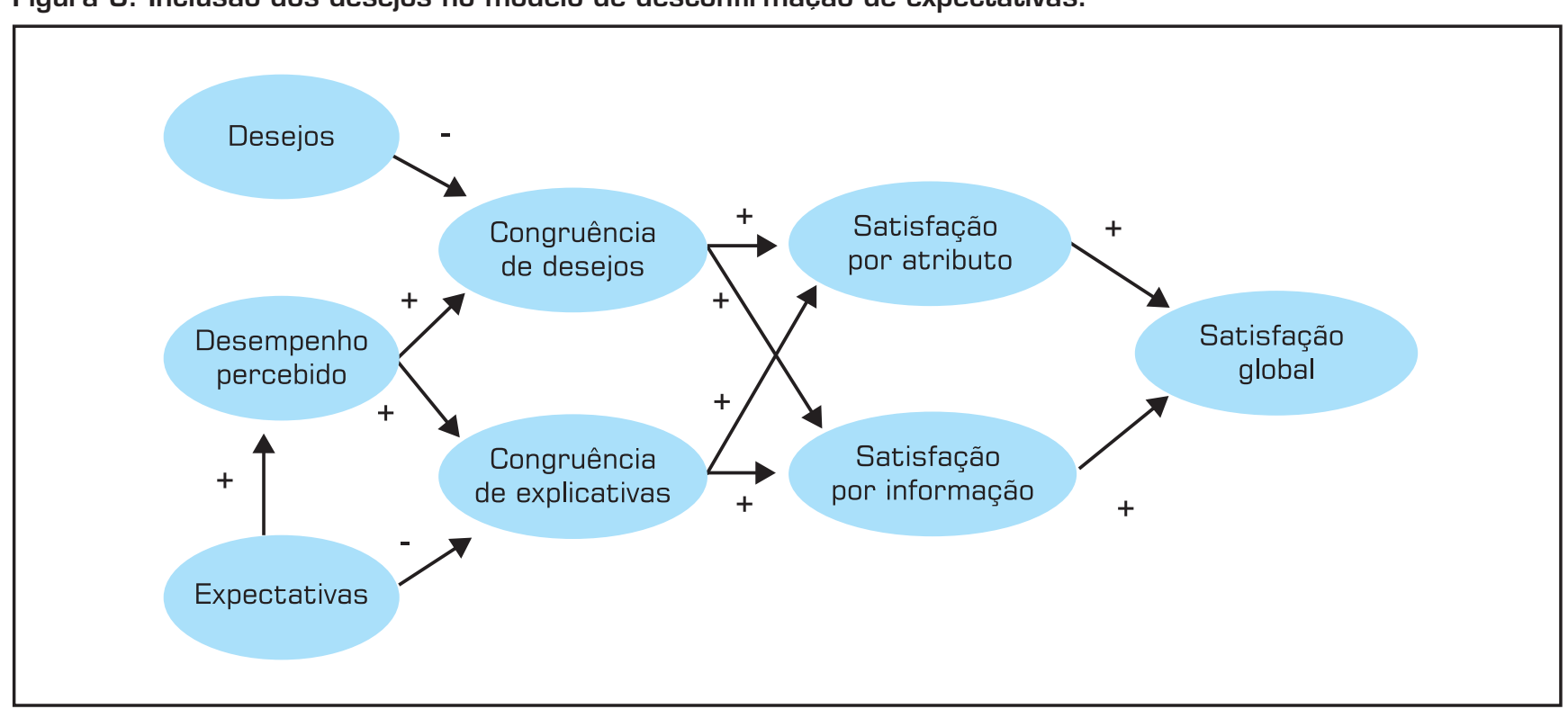

Fonte: Adaptado de Spreng et al. (1996). 
- Modelos de satisfação do consumidor em nível macro Em função da importância da satisfação do consumidor para as empresas e para a qualidade de vida, muitos países têm atualmente um índice nacional para medir e acompanhar a satisfação dos clientes em nível macro (ZEITHAML, 2003; MORGAN; REGO, 2006). O índice de satisfação do consumidor americano (American Customer Satisfaction Index - ACSI) é um tipo de medida de desempenho de mercado para empresas, indústrias, setores econômicos e economias nacionais. $\mathrm{O}$ índice mede a qualidade dos bens e serviços do ponto de vista do consumidor (FORNELL et al., 1996). Segundo esses autores, os determinantes deste modelo de satisfação (ACSI) são três: a qualidade percebida, o valor percebido e as expectativas do cliente. O modelo é apresentado na Figura 4.

Gonçalves Filho et al. (2004) mensuraram a satisfação em instituições de ensino superior no Brasil aplicando o modelo ACSI. Os resultados da pesquisa demonstram que, dentre os determinantes do modelo de satisfação, a qualidade percebida e o valor são os construtos que têm maior impacto sobre a satisfação na amostra estudada. As expectativas não afetam significativamente a satisfação nem o valor percebido do cliente. Estes resultados sugerem que o modelo ACSI não é totalmente aplicável à população em estudo, uma vez que dois caminhos do modelo não foram significativos.

- A influência da imagem na satisfação do consumidor

Andreassen e Lindestad (1998) examinaram o impacto da imagem corporativa na qualidade, satisfação e lealdade do consumidor com serviços complexos, caracterizados por atributos de qualidade difíceis de avaliar. $\mathrm{O}$ modelo proposto sugere que a qualidade percebida e a imagem corporativa exercem uma grande influência na satisfação do cliente, enquanto o valor não afeta significativamente a satisfação, como é apresentado na Figura 5.

Conforme esses autores, a imagem é estabelecida e desenvolvida na mente do consumidor através da comunicação e experiência. A imagem corporativa é um dos determinantes na escolha da empresa pelo consumidor quando os atributos do serviço são difíceis de avaliar e, se o serviço retribuído ao cliente é satisfatório do seu ponto de vista, as atitudes e intenções serão favoráveis para a empresa. Desta forma, essa imagem desempenha um papel importante para atrair e reter clientes.

\section{- A influência do valor e a qualidade na satisfação do consumidor}

Day (2002) estudou o papel do valor na satisfação do cliente realizando uma pesquisa qualitativa e obtendo os seguintes resultados: o valor não é sempre considerado pelo consumidor na escolha do produto; a estimação do valor de um serviço é mais difícil do que a apreciação do valor de um produto; as expectativas do cliente afetam grandemente a estimação de valor e a satisfação/insatisfação está ligada às percepções de valor em muitas, mas não em todas as compras. Conforme esse autor, o valor não é necessariamente um antecedente ou conseqüência da satisfação do cliente.

Por outro lado, Choi et al. (2004) avaliaram a influência do valor e da percepção de qualidade na satisfação do cliente e suas intenções comportamentais para serviços de cuidados à saúde, no contexto do mercado da Coréia do Sul. Os resultados obtidos são apresentados no modelo da Figura 6. Este

Figura 4: Modelo do Índice de Satisfação do Consumidor Americano (ACSI).

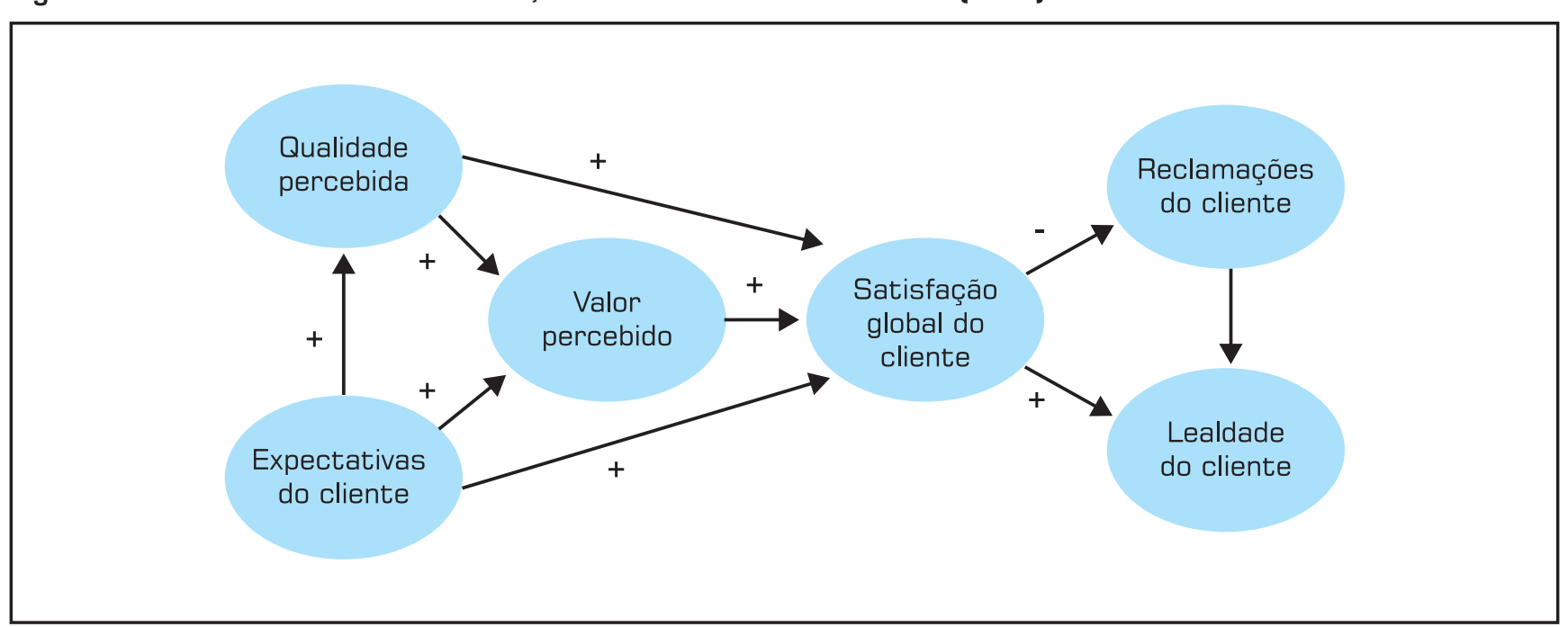

Fonte: Adaptado de Fornell et al. (1996). 
modelo confirma as pesquisas dos autores Wang e Lo (2002) e Cronin Jr. et al. (2000), em que a qualidade de serviço e o valor constituem os determinantes principais da satisfação, sendo que a qualidade de serviço exerce maior influência na satisfação do que o valor para este tipo de serviço. Assim, a qualidade do serviço afeta positivamente o valor percebido pelo paciente e as intenções comportamentais são influenciadas pela satisfação do cliente, pela qualidade do serviço e pelo valor. Da mesma forma, Collier e Bienstock (2006) observaram uma grande influência da qualidade percebida sobre a satisfação dos clientes e as intenções de recompra para serviços de Internet de empresas varejistas.

\section{- A influência das percepções do consumidor na satis- fação}

Bei e Chiao (2001) avaliaram os efeitos das percepções dos clientes sobre a satisfação e lealdade do cliente. Os autores integram em um mesmo modelo as qualidades do produto (tangíveis) e do serviço (intangíveis) e o preço como determinantes diretos da satisfação, conforme apresentado na Figura 7.

Assim, as percepções de qualidade do produto, qualidade do serviço e a justiça do preço afetam direta e positivamente a satisfação do cliente e possuem quase o mesmo grau de importância. A satisfação do cliente atua como mediador entre estes determinantes e a lealdade do cliente. A qualidade do serviço percebida afeta indiretamente a lealdade através da satisfação, enquanto que a qualidade do produto e a justiça do preço percebida possuem influência direta e indireta na lealdade. Isto se deve a que o serviço é considerado intangível e os consumidores só podem formar suas atitudes para com a qualidade do serviço através da percepção (BEI; CHIAO, 2001).

\section{- Serviços}

O setor de serviços desempenha um papel fundamental na economia mundial, e sua importância pode ser verificada através do seu aporte no Produto Interno Bruto (PIB), na geração de empregos e pelos benefícios gerados ao setor industrial, oferecendo um diferencial competitivo para muitas empresas, fornecendo suporte às atividades de manufatura e gerando lucro (GIANESI; CORRÊA, 1994). Nos países desenvolvidos, o setor de serviços ocupa posição de destaque na economia e, no Brasil, a tendência não se mostra diferente. Nas últimas décadas, o setor de serviços representa quase dois terços do emprego urbano metropolitano e responde por mais da metade do PIB brasileiro (MELO et al., 1998, p. 1).

A importância crescente dos serviços na economia brasileira e mundial sugere a necessidade de desenvolver conceitos e técnicas de administração dirigidas unicamente para este setor, considerando a diversidade e complexidade de suas operações, de modo a estabelecer as apropriadas políticas de marketing que satisfaçam as necessidades dos diferentes nichos de mercado. Pasupathy (2007) afirma que é crescente a necessidade de investimento nos atributos operacionais dos serviços, considerando o seu impacto nas percepções dos consumidores, intenções comportamentais, lealdade, penetração de mercado e nos lucros das empresas.

Definir serviços é um tema complexo, devido à grande variedade de atividades que estão incluídas. Também é difícil distinguir serviços "puros" e produtos "puros",

Figura 5: Modelo estrutural de satisfação para serviços complexos.

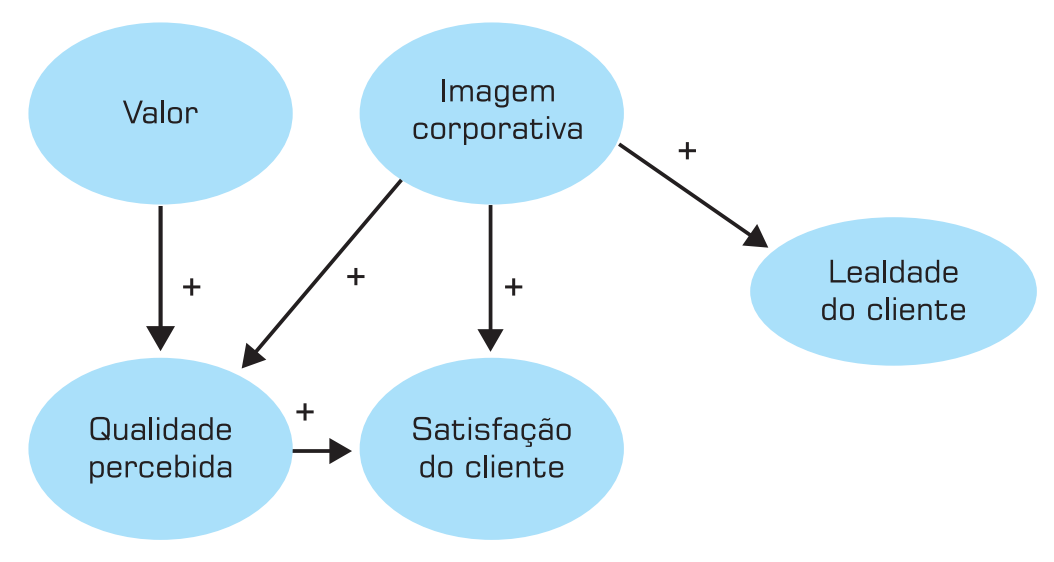

Fonte: Baseado no modelo proposto por Andreassen e Lindestad (1998). 
pois a aquisição de um produto geralmente está acompanhada de algum serviço e a compra de um serviço, na maioria dos casos, está associada a bens físicos (FITZSIMMONS; FITZSIMMONS, 2000). Segundo Bateson e Hoffman (2001), um produto "puro" é aquele que uma vez adquirido pelo consumidor é levado embora com ele para consumo ou uso, enquanto que um serviço "puro" é aquele benefício oferecido ao consumidor que não está relacionado com bens físicos, portanto, não pode ser consumido ou usado.
Do ponto de vista de Fitzsimmons e Fitzsimmons (2000, p. 43), "um serviço consiste de um pacote de benefícios implícitos e explícitos, executado dentro de instalações de suporte e utilizando-se de bens facilitadores". Na definição anterior, os benefícios implícitos são aqueles que o consumidor aprecia vagamente e que constituem as características extrínsecas do serviço, enquanto que os benefícios explícitos estão relacionados com as características intrínsecas ou essenciais do serviço. As instalações de suporte representam os estabelecimentos onde é produzido

Figura 6: Modelo de satisfação do consumidor para serviços de cuidado à saúde.

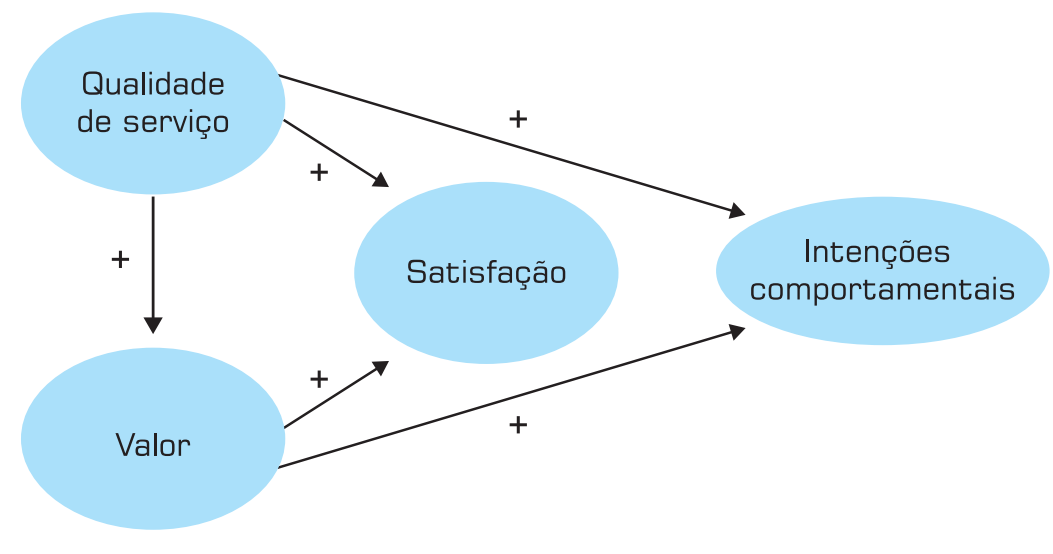

Fonte: Adaptado de Choi et al. (2004).

Figura 7: Modelo integrado dos efeitos das percepções dos clientes na satisfação.

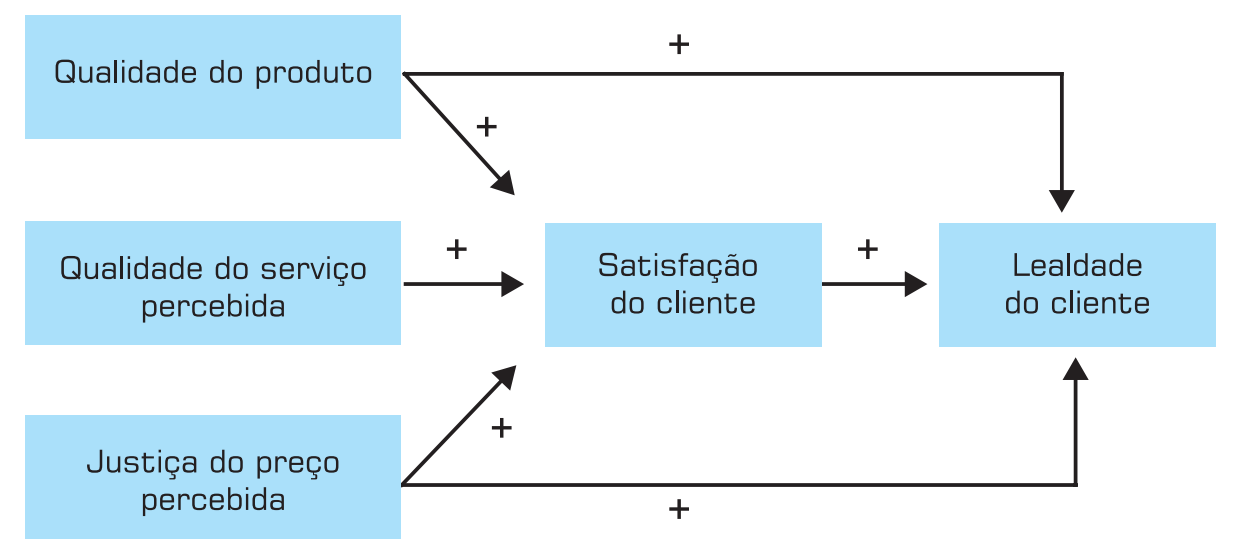

Fonte: Adaptado de Bei e Chiao (2001). 
o serviço, e os bens facilitadores constituem os itens ou bens físicos envolvidos na prestação do serviço.

$\mathrm{Na}$ definição anterior considera-se que os serviços podem estar ou não acompanhados de bens físicos como parte da oferta de uma empresa ao mercado. Kotler (1998) classifica as ofertas de mercado em cinco categorias:

1. Bem tangível: nenhum serviço acompanha o produto.

2. Bem tangível acompanhado de serviços: a oferta consiste em um bem tangível e um ou mais serviços adicionais para atingir outras necessidades dos consumidores.

3. Híbrido: são oferecidas partes iguais de bens e serviços.

4. Serviço principal acompanhado de bens e serviços secundários: a oferta é constituída por um serviço principal que exige outros serviços adicionais e/ou bens de apoio.

5. Serviço: o benefício oferecido consiste em apenas um serviço.

Algumas características importantes que diferenciam os serviços dos produtos são (GIANESI; CORRÊA, 1994; PASUPATHY, 2007):

- Os serviços são intangíveis: são experiências que o cliente vivencia. Essa intangibilidade torna difícil para os gerentes avaliar o resultado e a qualidade do serviço.

- Necessitam da presença do cliente para sua produção: o cliente é o elemento que inicia a operação e, muitas vezes, decide quando e como deve realizar-se.

- A produção e o consumo de serviços são simultâneos: geralmente não há etapa intermediária entre a produção de um serviço e seu consumo por parte de um cliente. Como conseqüência, os serviços não podem ser estocados e isto dificulta o uso eficiente da capacidade produtiva do prestador de serviço.

\section{Modelagem de equações estruturais}

A modelagem de equações estruturais, também conhecida como SEM (structural equations modeling), é uma técnica que pode ser vista como uma extensão da regressão múltipla, que permite a estimação simultânea de diversas equações, considerando a existência de mais de uma variável dependente. Portanto, uma das características básicas da SEM é que se pode testar uma teoria de ordem causal entre um conjunto de variáveis (KLEM apud FARIAS; SANTOS, 2000).

No caso da satisfação do cliente, por exemplo, a literatura propõe que o desempenho percebido pelo cliente influencia a desconfirmação de expectativas, e que essa, por sua vez, pode levar à satisfação (OLIVER, 1980). Essas relações causais podem ser verificadas com o uso de equações estruturais. Conforme Hair et al. (1998, p. 578), as equações estruturais têm sido amplamente utilizadas em vários cam- pos de estudo, como marketing, gestão, comportamento organizacional, entre outros. Este fato deve-se às seguintes vantagens: (1) a técnica provê um método para lidar com múltiplos relacionamentos simultaneamente enquanto provê eficiência estatística e, (2) é hábil avaliando os relacionamentos de forma abrangente, provendo uma transição da análise exploratória a confirmatória.

\section{para a qualidade de vida, muitos países têm atualmente um índice nacional para medir e a satisfação dos clientes.}

O ponto inicial para a aplicação da modelagem de equações estruturais é a existência de um esquema teórico ou modelo conceitual que especifique as relações entre um conjunto de variáveis. Para efetivar a análise, faz-se necessário um conjunto de dados para cada variável do modelo. O número de casos necessários depende da complexidade do modelo. Klen (apud FARIAS; SANTOS, 2000, p. 116) sugere de 200 a 300 casos para cada modelo.

A modelagem de equações estruturais é uma técnica avançada de tratamento e análise estatística de dados. Mas, antes do uso da modelagem de equações estruturais, devese ponderar a respeito de aspectos como, por exemplo, a necessidade de se ter amostras grandes e cada vez maiores à medida que os modelos se tornam complexos. (GOSLING; GONÇALVES, 2003).

Conforme Hair et al. (1998), o tamanho da amostra impacta substancialmente a significância estatística das técnicas multivariadas, incluindo neste tipo a modelagem de equações multivariadas. Para amostras pequenas, a sofisticação e a complexidade da técnica pode resultar em: (i) pouca força estatística para gerar resultados significativos ou (ii) dados facilmente ajustados, de modo que os resultados se ajustam perfeitamente aos dados, mas, podem não ter generalização. Um efeito similar pode acontecer com amostras muito grandes, as quais podem tornar os testes estatísticos muito sensíveis.

\section{MODELAGEM PROPOSTA}

Uma das técnicas mais utilizadas para a modelagem da satisfação do cliente é a análise de equações estruturais. Contudo, este método ainda não é muito utilizado no Brasil, tanto pela complexidade dos cálculos como pela necessidade de um tamanho de amostra muito grande (SCHULER apud 
URDAN; RODRIGUES, 1999). O método proposto neste trabalho representa uma nova abordagem para a construção de modelos causais de satisfação dos clientes de serviços, seguindo procedimentos mais simples e sem a necessidade de grandes tamanhos de amostra.

A modelagem proposta pode ser dividida em três etapas: (1) definição dos determinantes a serem incluídos no modelo, (2) aplicação da pesquisa e (3) construção do modelo.

\section{Definição dos determinantes para a construção do modelo}

O primeiro passo antes da construção do instrumento de coleta de dados é a definição dos determinantes a serem incluídos no modelo de satisfação do consumidor e, sobre os quais são elaboradas as questões. Para tanto, é realizado encontrados na literatura e identificados os principais determinantes que afetam diretamente à satisfação do cliente e que são considerados na maioria das pesquisas.

A análise dos modelos da literatura sugere que grande parte dos modelos de satisfação do cliente considera como os principais determinantes da satisfação o modelo cognitivo de desconfirmação de expectativas, as expectativas prévias dos clientes, a qualidade percebida, o desempenho percebido e o valor percebido. Porém, vários autores preocuparam-se em estudar outros aspectos psicológicos e afetivos dos clientes dentro do modelo, que podem ter forte influência sobre a satisfação em determinadas situações. um estudo dos modelos de satisfação dos consumidores

ção dos consumidores para o tipo de serviço estudado, foram selecionados os seguintes determinantes, incluindo a variável satisfação dos consumidores, para a elaboração do instrumento de coleta de dados e, conseqüentemente, para a construção do modelo no presente estudo: desejos pessoais dos clientes, expectativas dos clientes, emoções vivenciadas no momento da prestação de serviço, qualidade percebida pelo cliente, preço do serviço percebido pelo cliente, valor do serviço percebido pelo cliente, desconfirmação de expectativas dos clientes, imagem corporativa e satisfação dos clientes.

O desempenho percebido não foi considerado entre os determinantes selecionados para o estudo, pois existem divergências nas definições encontradas na literatura entre desempenho e qualidade percebida. Segundo Fornell et al. (1996), a qualidade percebida pode ser vista também como desempenho percebido. Portanto, para os efeitos desta pesquisa e construção dos modelos de satisfação foi utilizada a qualidade percebida pelo cliente como a avaliação geral da excelência do serviço.

\section{Aplicação da pesquisa}

Nesta etapa, é realizado o levantamento dos dados através da aplicação de uma pesquisa descritiva, tendo como finalidade identificar as relações entre os determinantes identificados, e a própria satisfação dos consumidores, de forma a estabelecer o modelo sistêmico a partir destes elementos, valendo-se do uso de técnicas e instrumentos para a coleta dos dados.

O instrumento de coleta de dados é constituído por um questionário fechado de nove perguntas a ser respondido pela pessoa que fornece as informações na presença do próprio pesquisador. Conforme Cervo e Bervian (2002), o questionário possibilita medir com melhor exatidão o que se deseja através de respostas às questões que o próprio informante preenche. Em função de sua flexibilidade, é o instrumento mais comum para coletar dados primários e, quando estruturado com questões fechadas, fornece

Importante esclarecer que os modelos encontrados na literatura não contemplam todos os determinantes em um modelo único. Isso acontece porque, geralmente, a metodologia utilizada envolve o emprego de equações estruturais, o que implica a exigência de medidas quantitativas de todos os determinantes mencionados, além de uma extensa base de dados, que permita a avaliação da existência de relação entre determinantes. Portanto, a grande maioria dos modelos pesquisados está focada no estudo de alguns poucos determinantes, considerados os mais importantes (ou referente aos quais foi possível reunir dados quantitativos), que afetam a satisfação dos consumidores.

Considerando a possibilidade de que alguns ou todos os elementos identificados na literatura possam afetar a satisfa- respostas mais fáceis de interpretar e tabular, pois são préespecificadas todas as respostas possíveis e os respondentes devem escolher entre elas (KOTLER, 1998).

As perguntas do questionário buscam determinar as relações existentes entre os elementos que constituem o modelo de satisfação dos clientes de serviços. Para isto, cada questão pergunta a dependência de cada uma das variáveis estudadas (desejos pessoais, expectativas, emoções vivenciadas no momento da prestação, qualidade percebida, preço percebido, valor do serviço, desconfirmação de expectativas, imagem corporativa e satisfação dos clientes) em relação às outras.

As questões podem ser respondidas utilizando múltipla escolha ou selecionando nenhuma das alternativas. Pode ser anexada ao questionário uma folha contendo as definições 
de cada um dos elementos envolvidos na pesquisa, de modo a homogeneizar os conceitos possuídos pelos entrevistados. O modelo do questionário e a folha com as definições estão apresentados nos apêndices.

Vale ressaltar que o método de pesquisa aplicado permite avaliar a existência de relações entre múltiplos determinantes, utilizando um procedimento mais simples, e com um tamanho de amostra menor do que o requerido nos procedimentos tradicionais de equações estruturais (em função da variabilidade presente nas respostas, observou-se que cerca de 40 respondentes são suficientes para a estruturação do modelo com a precisão desejada).

\section{Construção do modelo de satisfação do cliente}

Partindo da coleta dos dados dos questionários, identificase o total de respondentes que assinalou a existência de uma determinada relação entre determinantes. Os valores observados (contagens) são agrupados em uma matriz, onde o cabeçalho das linhas é constituído pelos determinantes, entendidos como variáveis dependentes, e o cabeçalho das colunas é constituído pelos mesmos determinantes, entendidos como varáveis independentes. Para determinar quais das relações entre os determinantes são significativas, realiza-se a análise dos resíduos padronizados. Os resíduos padronizados são calculados a partir da seguinte equação (AGRESTI; FINLEY, 1997):

$$
r_{i j}=\frac{f o-f e}{\sqrt{f e(1-\% \text { da linh })(1-\% \text { da coluna })}}
$$

Onde,

rij: resíduo padronizado;

fo: valor observado (no caso, a contagem obtida para cada determinante);

$f e$ : valor esperado (no caso, a média dos valores observados).

O percentual (\%) da linha é calculado somando os valores das contagens para cada variável dependente (cabeçalho das linhas) e dividindo esse valor pela soma total das contagens. O percentual (\%) da coluna é calculado da mesma forma, porém, utilizando as contagens das variáveis independentes (cabeçalho das colunas).

A análise de resíduos padronizados fornece informação em relação aos valores que se afastam do esperado. Além disso, estes resíduos padronizados se comportam como a variável reduzida z (AGRETI; FINLEY, 1997). Portanto, fazendo uso desta ferramenta, e fixando o número de desvios em relação à media dos valores observados, podem-se identificar as relações significativas entre os determinantes do modelo. Os valores significativos representam evidência estatística da existência de relação entre os determinantes em estudo.

Estas relações entre os determinantes são estabelecidas utilizando como critério de decisão valores de desvio maiores de $+2,0$. Estatisticamente, esse valor está associado aproximadamente a um nível de confiança alfa $=0,05$ (WERKEMA; AGUIAR, 1996). Explicando melhor o conceito de nível de confiança, tem-se que a probabilidade de um valor de resíduo padronizado maior de $+2,0$ ser obtido por acaso, sem que exista relação entre os determinantes envolvidos, é menor de 5\%. Assim, o modelo é construído incorporando somente as relações estatisticamente significativas.

A construção do diagrama de enlace causal é realizada a partir das variáveis identificadas através da pesquisa e seus relacionamentos, indicando o sentido de influência de uma variável sobre outra por meio de uma seta. Para o desenho dos diagramas de causa e efeito de cada modelo de satisfação dos consumidores é utilizado o software VENSIM, versão 5.

\section{APLICAC̄̃̃ PRÁTICA}

A aplicação prática do método proposto para a modelagem da satisfação do cliente foi realizada para o serviço oferecido pelos restaurantes à la carte. Para isto, foi selecionada uma amostra constituída por moradores de Porto Alegre, consumidores atuais do serviço de restaurante à la carte, todos com segundo grau concluído. A opção por entrevistar pessoas com maior formação foi feita em função da complexidade da terminologia utilizada na pesquisa.

O tamanho da amostra foi de 40 clientes, sendo validado a partir da análise dos resíduos padronizados. Uma vez que os valores de resíduos padronizados revelaram diferenças estatisticamente significativas entre os diversos determinantes, o tamanho da amostra definida inicialmente para a realização da pesquisa foi considerado adequado.

As contagens das respostas dos questionários aplicados aos clientes de restaurantes à la carte foram compiladas em uma matriz apresentada na Tabela 1.

Analisando-se a primeira linha, pode-se observar que duas (2) respostas indicaram que a imagem corporativa depende dos desejos pessoais; treze (13) respostas apontaram que a imagem corporativa depende das expectativas; outras sete (7) indicaram que esta imagem depende das emoções vivenciadas; vinte e cinco (25) respostas foram dadas para a dependência da imagem com a qualidade percebida; cinco (5) respostas para a dependência da imagem com o preço do serviço; seis (6) respostas indicaram que a imagem corporativa depende do valor do serviço; doze (12) indicaram que a imagem depende da confirmação de expectativas e vinte e sete (27) respostas foram dadas para a dependência da imagem com a satisfação do consumidor. $\mathrm{O}$ mesmo tipo de análise pode ser realizado para os outros determinantes estudados. 
A Tabela 2 mostra os valores de resíduos padronizados determinados a partir da equação 1 para cada uma das relações entre determinantes.

Considerando que os resíduos se comportam como a variável reduzida z (AGRESTI; FINLEY, 1997), estabeleceuse como critério de decisão para aceitar a existência de relação significativa entre os determinantes do modelo valores de desvio maiores de dois $(+2,0)$. Este valor está associado a um nível de confiança de 5\%, usualmente empregado nos estudos de engenharia e ciências sociais.

Os desvios achureados da Tabela 2 representam valores estatisticamente significativos, que se afastam consideravelmente da média esperada, e, portanto, evidenciam a existência de relações entre os respectivos determinantes. Partindo da análise de resíduos podem-se identificar as relações causais entre os determinantes envolvidos e desvendar a estrutura de relações que caracteriza o contexto dos restaurantes à la carte. A Figura 8 apresenta o diagrama de enlace causal gerado da integração de todos os determinantes e suas influências dentro de uma estrutura sistêmica. O modelo foi desenhado utilizando o software VENSIM, versão 5.

A análise da Figura 8 sugere a existência de um enlace ou feedback entre a qualidade percebida, a confirmação de expectativas e a satisfação do consumidor. Estes elementos formam a base do modelo de satisfação do consumidor de restaurante à la carte e influenciam-se mutuamente direta e indiretamente. Um aumento na qualidade percebida pelos clientes com o serviço dos restaurantes à la carte gera maior confirmação de suas expectativas prévias, incrementando desta forma, sua satisfação geral com o benefício obtido deste serviço, o que, por sua vez, volta a influenciar a qualidade percebida e assim por diante.

Outro enlace ou feedback ocorre quando um aumento na satisfação do consumidor gera novas expectativas nos clientes, estas novas expectativas, por sua vez, afetam os desejos pessoais do consumidor em relação ao serviço do restaurante à la carte, estes desejos podem afetar as emoções (positivas ou negativas) vivenciadas no momento da prestação do serviço, gerando satisfação (ou não) no consumidor. A satisfação com o serviço e as emoções vivenciadas no momento da refeição, influenciam-se direta e mutuamente.

Por último, a percepção de valor do serviço nos clientes e a imagem que eles possuem sobre o restaurante à la carte são afetadas pela satisfação e pela qualidade percebida. Esta qualidade é a responsável pela percepção do preço que os clientes possuem em relação ao benefício obtido deste tipo de serviço.

\section{DISCUSSÃO DOS RESULTADOS}

Entre os modelos estudados na literatura de satisfação do consumidor, não existe nenhum modelo que se ajuste ao modelo de causa e efeito obtido para o serviço de restaurante à la carte estudado (Figura 8). De fato, poucos estudos têm

Tabela 1: Contagens de respostas dos questionários aplicados a clientes de restaurantes à la carte.

\begin{tabular}{|c|c|c|c|c|c|c|c|c|c|c|}
\hline & & \multicolumn{9}{|c|}{ Variáveis independentes } \\
\hline \multicolumn{2}{|r|}{ Restaurante à la carte } & $\begin{array}{l}\underline{\varepsilon} \\
\text { Dू } \\
\text { D } \\
\underline{\varepsilon}\end{array}$ & 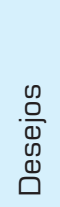 & 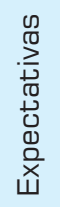 & 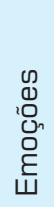 & $\begin{array}{l}\frac{0}{0} \\
\frac{\pi}{\pi} \\
\frac{0}{0} \\
\frac{\pi}{2} \\
0\end{array}$ & 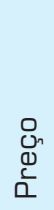 & $\frac{5}{\frac{0}{10}}$ & 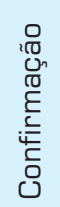 & 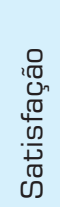 \\
\hline \multirow{9}{*}{ 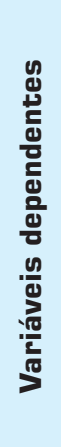 } & Imagem & & 2 & 13 & 7 & 25 & 5 & 6 & 12 & 27 \\
\hline & Desejos & 5 & & 24 & 17 & 15 & 5 & 7 & 15 & 14 \\
\hline & Expectativas & 17 & 20 & & 7 & 13 & 7 & 4 & 9 & 23 \\
\hline & Emoções & 4 & 27 & 16 & & 20 & 5 & 8 & 16 & 26 \\
\hline & Qualidade & 7 & 11 & 20 & 12 & & 6 & 18 & 18 & 27 \\
\hline & Preço & 8 & 3 & 10 & 5 & 26 & & 18 & 14 & 20 \\
\hline & Valor & 2 & 13 & 14 & 14 & 28 & 19 & & 18 & 23 \\
\hline & Confirmação & 3 & 8 & 15 & 13 & 24 & 7 & 15 & & 32 \\
\hline & Satisfação & 7 & 19 & 17 & 24 & 27 & 11 & 18 & 32 & \\
\hline
\end{tabular}

Fonte: Elaborada pelos autores. 
pesquisado múltiplas relações entre os determinantes mais importantes do modelo de satisfação do consumidor (CRONIN et al., 2000). Os modelos identificados na literatura contemplam alguns dos determinantes estudados e algumas das relações obtidas, mas não todas. Comparando o modelo obtido na aplicação prática da modelagem proposta com os modelos apresentados na literatura (descritos no referencial teórico), encontraram-se algumas convergências e outras divergências que são detalhadas a continuação.

As principais convergências existentes entre os modelos obtidos e os modelos apresentados na literatura são:

- A qualidade percebida como determinante direto da satisfação do consumidor de serviços. O modelo de satisfação obtido para o serviço de restaurante à la carte confirma as pesquisas da literatura (e.g., FORNELL et al., 1996; ANDREASSEN; LENDESTAD, 1998; CHOI et al., 2004) em relação à influência direta da qualidade percebida sobre a satisfação do consumidor dos serviços estudados.

- A confirmação de expectativas como determinante direto da satisfação do consumidor de serviços. O modelo obtido sugere que, quando os consumidores comparam as percepções de desempenho do produto com suas expectativas, são gerados sentimentos de satisfação (ou insatisfação) em relação ao serviço. Resultado que ratifica as pesquisas vários autores na literatura (e.g., OLIVER, 1980; CHURCHILL; SURPRENANT, 1982; BEARDEN; TEEL, 1983).
- O valor do serviço é afetado pela qualidade percebida do cliente. Desta forma, os consumidores de restaurantes à la carte parecem dar maior importância à qualidade do que ao custo associado à compra do serviço. Autores como Fornell et al. (1996), Andreassen e Lindestad (1998), Choi et al. (2004) e Cronin et al. (2000) obtiveram o mesmo resultado.

As emoções vivenciadas no momento da prestação de serviço afetam a satisfação do cliente de restaurantes à la carte. O modelo obtido confirma as pesquisas de Oliver (1993) e Jun et al. (2001) em relação ao papel da experiência afetiva na satisfação do cliente. Desta forma, os sentimentos positivos ou negativos que o cliente vivencia no momento da refeição, com os garçons, atendentes e, em geral, com o somatório de experiências positivas e negativas com o serviço, podem afetar a sua satisfação.

A seguir são detalhadas as principais divergências encontradas entre o modelo obtido e os modelos pesquisados na literatura:

Algumas pesquisas (e.g., FORNELL et al., 1996; CHOI et al., 2004; CRONIN et al., 2000) sugerem que o valor do serviço é um determinante direto da satisfação do consumidor. Porém, o modelo obtido para o serviço de restaurantes à la carte aponta o valor como uma conseqüência da satisfação do consumidor. Esta divergência pode ser justificada pela complexidade da estimação do valor de um serviço em relação à apreciação de valor de um produto. O valor não é sempre considerado pelo consumidor na escolha do serviço (DAY, 2002).

Tabela 2: Análise de resíduos padronizados para o serviço de restaurante à la carte.

\begin{tabular}{|c|c|c|c|c|c|c|c|c|c|c|}
\hline & & \multicolumn{9}{|c|}{ Variáveis independentes } \\
\hline & Restaurante à la carte & 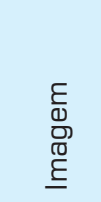 & 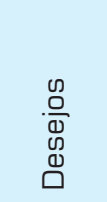 & 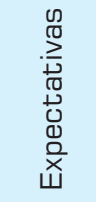 & 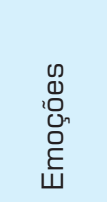 & $\begin{array}{l}\frac{0}{0} \\
\frac{\pi}{0} \\
\frac{0}{0} \\
\frac{10}{3} \\
0 \\
0\end{array}$ & 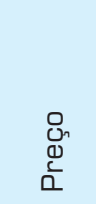 & $\frac{5}{\frac{0}{10}}$ & 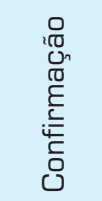 & 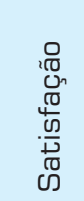 \\
\hline \multirow{9}{*}{ 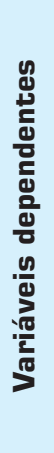 } & Imagem & & $-3,64$ & $-0,45$ & $-2,18$ & 3,16 & $-2,71$ & $-2,46$ & $-0,75$ & 3,80 \\
\hline & Desejos & $-2,70$ & & 2,79 & 0,71 & 0,14 & $-2,72$ & $-2,18$ & 0,14 & $-0,17$ \\
\hline & Expectativas & 0,70 & 1,59 & & $-2,19$ & $-0,47$ & $-2,15$ & $-3,05$ & $-1,64$ & 2,58 \\
\hline & Emoções & $-3,02$ & 3,66 & 0,43 & & 1,67 & $-2,75$ & $-1,91$ & 0,44 & 3,54 \\
\hline & Qualidade & $-2,16$ & $-1,04$ & 1,62 & $-0,74$ & & $-2,46$ & 1,01 & 1,03 & 3,84 \\
\hline & Preço & $-1,86$ & $-3,36$ & $-1,34$ & $-2,77$ & 3,48 & & 1,00 & $-0,16$ & 1,67 \\
\hline & Valor & $-3,61$ & $-0,46$ & $-0,16$ & $-0,16$ & 4,14 & 1,29 & & 1,04 & 2,62 \\
\hline & Confirmação & $-3,30$ & $-1,92$ & 0,14 & $-0,45$ & 2,89 & $-2,17$ & 0,13 & & 5,38 \\
\hline & Satisfação & $-2,20$ & 1,33 & 0,75 & 2,82 & 3,89 & $-1,04$ & 1,03 & 5,31 & \\
\hline
\end{tabular}

Fonte: Elaborada pelos autores. 
As pesquisas de Andreassen e Lindestad (1998) sugerem que a imagem corporativa exerce uma grande influência na satisfação do consumidor e na qualidade percebida para serviços complexos que são adquiridos com pouca freqüência. $\mathrm{O}$ modelo obtido nesta pesquisa diverge do resultado anterior, pois a imagem corporativa é vista como uma conseqüência da qualidade percebida e da satisfação do consumidor. A divergência dos resultados pode ser explicada pela natureza do contexto avaliado em cada caso.

\section{CONCLUSÕES}

Este estudo apresentou uma nova abordagem para a modelagem das relações entre os determinantes da satisfação dos clientes de serviços. Neste sentido, se propôs uma metodologia baseada em três etapas: (i) definição dos determinantes a serem incluídos no modelo, (ii) instrumento de coleta de dados e (iii) construção do modelo.

A primeira etapa teve como objetivo principal a identificação dos principais determinantes que afetam a satisfação dos clientes, fundamentando-se nos modelos apresentados na literatura. Desta forma, minimizou-se um dos erros críticos no desenvolvimento de modelos com base teórica, que é a omissão de variáveis independentes que afetam o construto a ser avaliado (satisfação do cliente), também chamado de erro de especificação. Segundo Hair et al. (1998), todos os modelos de equações estruturais estão expostos a esse erro potencial.

A segunda etapa consistiu no levantamento dos dados através de uma pesquisa descritiva utilizando um questionário fechado aplicado aos clientes do serviço avaliado (restaurantes à la carte), com a finalidade de determinar as relações existentes entre os determinantes do modelo de satisfação do cliente.

Finalmente, na terceira etapa, foram tratados estatisticamente os dados obtidos da pesquisa e foram identificadas as relações significativas entre os determinantes, através da análise dos resíduos padronizados. Uma vez identificadas as relações entre os determinantes e suas influências, foi desenhado o diagrama de enlace causal que caracteriza a satisfação do cliente do serviço estudado (restaurante à la carte).

As principais vantagens do método proposto em relação aos métodos tradicionais de modelagem, como por exemplos as equações estruturais são: (i) possibilidade de identificar as relações entre múltiplos determinantes sem necessidade de um tamanho de amostra muito grande; (ii) utilização de um procedimento estatístico muito mais simples, baseado

Figura 8: Modelo de causa e efeito da satisfação dos clientes de restaurantes à la carte.

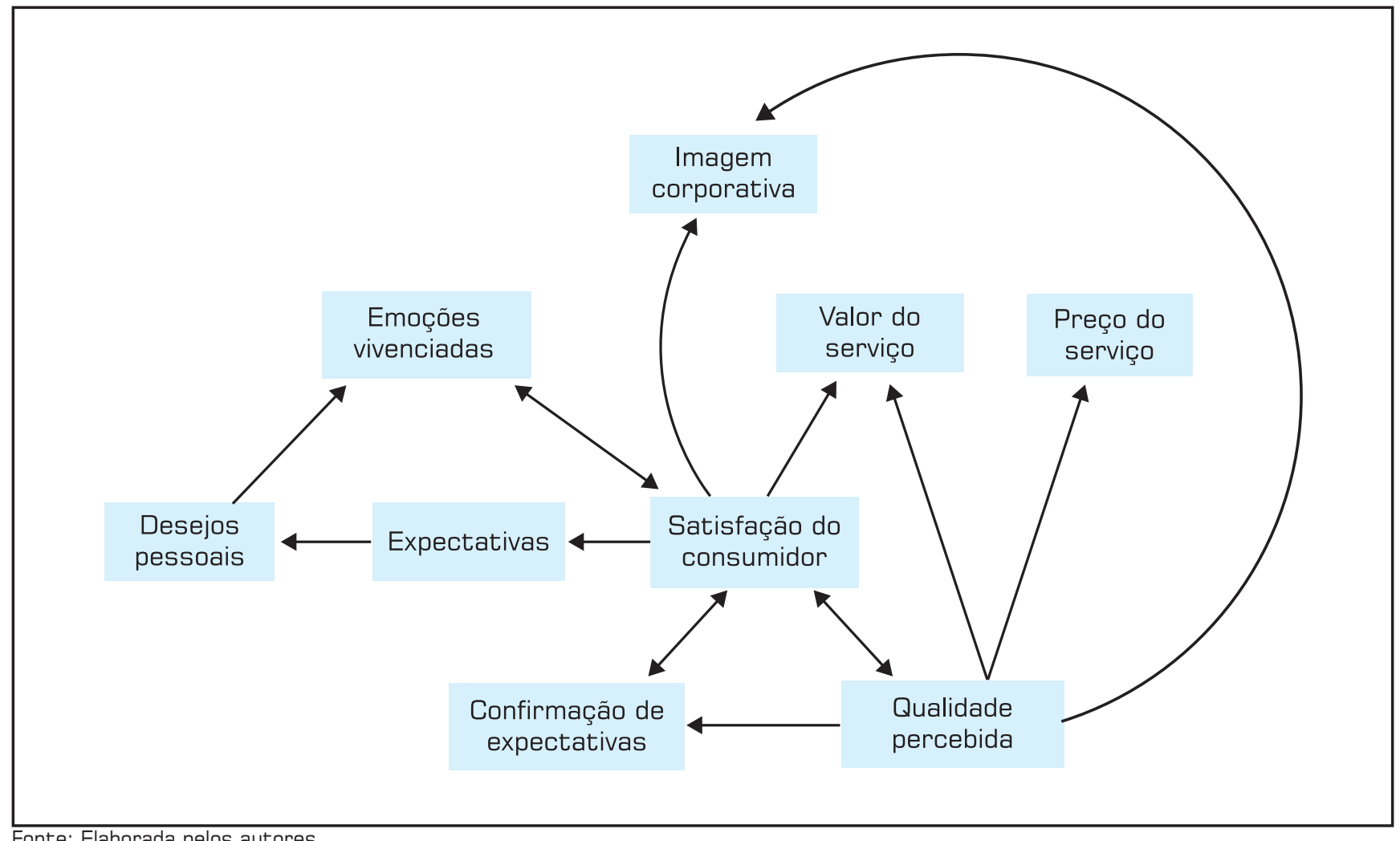


fundamentalmente na análise de resíduos padronizados, para a identificação de relações significativas; e (iii) possibilidade de minimizar o erro de especificação no processo de modelagem, visto que podem ser consideradas todas as variáveis independentes de efeito relevante sem tornar o modelo muito complexo.

Em relação ao modelo obtido para o serviço de restaurantes à la carte, conclui-se que poucos estudos da literatura têm pesquisado múltiplas relações entre os determinantes mais importantes do modelo de satisfação do consumidor. Os modelos identificados na literatura contemplam alguns dos determinantes estudados e algumas das relações obtidas neste trabalho, mas não todas. As principais convergências existentes entre o modelo obtido e os modelos apresentados na literatura são: (i) a qualidade percebida como determinante direto da satisfação do consumidor; (ii) a confirmação de expectativas como determinante direto da satisfação do cliente; (iii) o valor do serviço é afetado pela qualidade percebida do cliente; e (iv) as emoções vivenciadas no momento da prestação de serviço afetam a satisfação do cliente.
As principais divergências existentes entre o modelo obtido e os modelos apresentados na literatura são: (i) algumas pesquisas (e.g., FORNELL et al., 1996; CHOI et al., 2004; CRONIN et al., 2000) sugerem que o valor do serviço é um determinante direto da satisfação do consumidor, contudo, o modelo obtido para o serviço de restaurante á la carte aponta o valor como uma conseqüência da satisfação do consumidor; (ii) as pesquisas de Andreassen e Lindestad (1998) sugerem que a imagem corporativa exerce uma grande influência na satisfação do consumidor e na qualidade percebida para serviços complexos que são adquiridos com pouca freqüência. O modelo obtido para o serviço estudado neste trabalho diverge do resultado anterior, pois a imagem corporativa é vista como uma conseqüência da qualidade percebida e da satisfação do consumidor.

A importância deste trabalho reside na sua contribuição com as pesquisas realizadas no setor de serviços e com os estudos que vêm se realizando para modelar a satisfação dos consumidores, temas de grande importância no âmbito empresarial atual.

\section{Artigo recebido em 16/11/2006 Aprovado para publicação em 27/09/2007}

\section{- References}

AGRESTI, A.; FINLEY, B. Statistical Methods for Social Sciences. 3. ed. Upper Saddle River, NJ: Prentice Hall, 1997.

ANDERSON, E. W.; FORNELL, C.; LEHMANN, D. R. Customer Satisfaction, Market Share, and Profitability: Findings from Sweden. Journal of Marketing, v. 58, n. 3, p. 53 (14), Jul. 1994.

ANDREASSEN, T. W.; LINDESTAD, B. Customer loyalty and complex services - The impact of corporate image on quality, customer satisfaction and loyalty for customers with varying degrees of service expertise. International Journal of Service Industry Management, v. 9, n. 1, p. 7-23, 1998.

APPLETON-KNAPP, S. L.; KRENTLER, K. A. Measuring Student Expectations and Their Effects on Satisfaction: The Importance of Managing Student Expectations. Journal of Marketing Education, v. 28, p. 254-264, 2006.

BATESON, J. E. G.; HOFFMAN, K. Douglas. Marketing de Serviços. Traduzido por Lúcia Simonini. 4. ed. Porto Alegre: Bookman, 834 p., 2001.
BEARDEN, W. O.; TEEL, J. E. Selected Determinants of Consumer Satisfaction and Complaint Reports. Journal of Marketing Research, v. 20, p. 21-28, Feb. 1983.

BEI L. T.; CHIAO, Y. C. An Integrated Model for the Effects of Perceived Product, Perceived Service Quality, and Perceived Price Fairness on Consumer Satisfaction and Loyalty. Journal of Consumer Satisfaction, Dissatisfaction and Complaining Behavior, v. 14, 2001.

CADOTTE, E. R.; WOODRUFF, R. B JENKINS, R. L. Expectations and Norms in Models of Consumer Satisfaction. Journal of Marketing Research, v. 24, p. 305-314, August 1987.

CERVO, A. L.; BERVIAN, P. A. Metodologia Científica. 5. ed. São Paulo: Prentice Hall, 242 p., 2002.

CHOI, K. S.; CHO, W. H. LEE, S. et al. The relationships among quality, value, satisfaction and behavioral intention in health care provider choice: A South Korean study. Journal of Business Research, v. 57, p. 913-921, 2004
CHURCHILL JR., G. A.; SURPRENANT, C. An Investigation into the Determinants of Customer Satisfaction. Journal of Marketing Research, v. 19, p. 491-504, Nov. 1982.

COLLIER, J. E.; BIENSTOCK, C. C. Measuring Service Quality in E-Retailing. Journal of Service Research, v. 8, p. 260 275, 2006

CRONIN JR., J. J.; BRADY, M. K.; HULT, G. Tomas. Assessing the effects of quality, value and customer satisfaction on consumer behavioral intentions in service environments. Journal of Retailing, v. 76, n. 2 , p. $193-218,2000$

DAY, E. The Role of Value in Consumer Satisfaction. Journal of Consumer Satisfaction, Dissatisfaction and Complaining Behavior, v. 15, 2002.

EVRARD, Y.; RODRIGUES, A. C. M. Uma Classificação de Serviços Baseada na Teoria Microeconômica da Informação. REAd - Revista Eletrônica de Administração, 1. ed., v. 1, n. 1, Programa de PósGraduação em Administração da Univ.
Federal do Rio Grande do Sul, Set - Out. de 1995.

FARIAS, S. A.; SANTOS, R. C. Modelagem de Equações Estruturais e Satisfação do Consumidor: uma investigação teórica e prática. $R A C$, v. 4, n. 3, Set/Dez 2000. Disponível em: <http://www.anpad.org. br/rac/vol_04/dwn/rac-v4-n3-sat.pdf > Acesso em: 25/05/2006.

FITZSIMMONS, J. A.; FITZSIMMONS, M. J. Administração de Serviços: operações, estratégia e tecnologia de informação. 2. ed. Porto Alegre: Bookman, 537 p., 2000.

FORNELL, C.; JOHNSON, M. D. ANDERSON, E. W. et al. The American Customer Satisfaction Index: Nature, purpose, and findings. Journal of Marketing, v. 60, n. 4, p. 7-12, Oct. 1996.

GIANESI, I. G. N.; CORRÊA, H. L. Administração Estratégica de Serviços: operações para a satisfação do cliente. São Paulo: Atlas, 233 p., 1994 


\section{- Referências}

GONCALVES FILHO, Cid : GUERRA, R. S : MOURA, A. I. Mensuração de Satisfação, Qualidade, Lealdade, Valor e Expectativa em Instituições de Ensino Superior: um estudo do modelo ACSI através de Equações Estruturais. Revista eletrônica de Gestão Organizacional, v. 2, n. 1, p. 5-18, jan./abr. 2004.

GOSLING, M.; GONCALVES, C. A Modelagem por Equações Estruturais: conceitos e aplicações. Revista FACES - Revista de Administração. Edição Ago/ Dez 2003. Disponível em: < http:www. revistafaces fumec.br/Resumo.aspx?cod $=3 \&$ codsumario $=06 \&$ codartigo $=01>$. Acesso em: 25/05/2006.

HAIR, JR. J. F.; ANDERSON, R. E.; TATHAM, R. L.; BLACK, W. C. Multivariate Data Analysis. Fifth edition. New Jersey: Prentice Hall, 666 p., 1998.

HOMBURG, C.; HOYER, W.; KOSCHATE, N. Customers' Reactions to Price Increases: Do Customer Satisfaction and Perceived Motive Fairness Matter?. Academy of Marketing Science. Journal, v. 33, n. 1, p. 36-49, Win. 2005.

JOHNSON, M. D.; ANDERSON, E. W.; FORNELL, C. Rational and adaptive performance expectations in a customer satisfaction framework. Journal of Consumer Research, v. 21, n. 4, p. 695 (12), March 1995

JOHNSON, M. D.; NADER, G.; FORNELL, C. Expectations, perceived performance, and customer satisfaction for a complex service: The case of bank loans. Journal of Economic Psychology, v. 17, p. 163182, 1996
JUN, Sunkyu; HYUN, Yong J.; GENTRY, James W. et al. The Relative Influence of Affective Experience on Consumer Satisfaction under Positive versus Negative Discrepancies. Journal of Consumer Satisfaction, Dissatisfaction and Complaining Behavior, v. 14, p. 141153, 2001.

KOTLER, P. Administração de Marketing: análise, planejamento, implementação e controle. Traduzido por Ailton Bomfim Brandão. 5. ed. São Paulo: Atlas, 725 p., 1998.

MELO, H. P.; ROCHA, F; FERRAZ, G. et al. O Setor de Serviços no Brasil: Uma visão global - 1985/95. Texto para Discussão $N^{o}$ 549, Rio de Janeiro, março de 1998.

MORGAN, N. A.; REGO, L. L. The Value of different customer satisfaction and loyalty metrics in predicting business performance. Marketing Science. v. 25, n. 5, p. $426-439,2006$

NASCIMENTO, J. R. A Satisfação do Cliente e sua Avaliação. Intervenção na Conferência sobre Retenção de Clientes. Lisboa, 26 e 27 de Maio de 1998. Disponível em: <http//www.terravista.pt/guincho/2022/satisfacao.html> Acesso em: 01 ago. 2004.

OLIVER, R. L. A Cognitive Model of the Antecedents and Consequences of Satisfaction Decisions. Journal of Marketing Research, v. 17, p. 460-469, Nov. 1980.
OLIVER, R. L. Cognitive, Affective, and Attribute Bases of the Satisfaction Response. Journal of Consumer Research, v. 20, p. 418-430, Dec. 1993.

OLSHAVSKY, R. W.; KUMAR, A. Revealing the Actual Roles of Expectations in Consumer Satisfaction with Experience and Credence Goods. Journal of Consumer Satisfaction, Dissatisfaction and Complaining Behavior, v. 14, p. 60-73, 2001.

PASUPATHY, K. S. A Framework to Evaluate Service Operations: dynamic service-profit chain. Quality Management Journal, v. 14, n. 3, p. 36-49, 2007.

SARAVANAN, R.; RAO, K. S. Service Quality from the Customer's Perspective: an empirical investigation. Quality Management Journal, v. 14, n. 3, p. 15-24, 2007.

SHETH, J.; BANWARI, M.; NEWMAN, B. I. Comportamento do Cliente: indo além do comportamento do consumidor. Traduzido por Lenita M. R. Esteves. São Paulo: Atlas, 795 p., 2001.

SPRENG, R. A.; MACKENZIE, S. B.; OLSHAVSKY, R. W. A reexamination of the determinants of consumer satisfaction. Journal of Marketing, v. 60, n. 3, p. 15-32, Jul. 1996.

TSE, D. K.; WILTON, P. C. Models of Consumer Satisfaction Formation: An Extension. Journal of Marketing Research, v. 25, p. 204-212, May 1988.
TSIROS, M.; MITTAL, V.; ROSS, W. Jr. The Role of Attributions in Customer Satisfaction: A Reexamination. Journal of Consumer Research, v. 31, n. 2, p. 476-483, Sep. 2004

URDAN, A. T.; RODRIGUES, A. R. Modelo do Índica de Satisfação do Cliente Norte-Americano: um exame inicial no Brasil com equações estruturais. RAC, v. 3, n. 3, Set/Dez 1999. Disponível em: $<$ http:www.anpad.org.br/rac/vol-03/ dwn/rac-v3-n3-atu.pdf > . Acesso em: 25/05/2006.

WANG, Y.; LO, Hing-Po. Service quality, customer satisfaction and behavior intentions: evidence from China's telecommunication industry. Info - The journal of policy, regulation and strategy for telecommunications, v. 4 , n. 6 , p. 50 60, Dec. 2002.

WERKEMA, M. C. C. Análise de regressão: como entender o relacionamento entre as variáveis de um processo. Belo Horizonte: Fundação Christiano Ottoni, 311p., c1996.

YI, Y. The determinants of consumer satisfaction: the moderating role of ambiguity. Advances in Consumer Research, v. 20, p. 502-506, 1993.

ZEITHAML, V. A. Marketing de Serviços: A Empresa com Foco no Cliente. 2. ed. Porto Alegre, RS: Bookman, 536 p. 2003.

\section{- Sobre os autores}

\section{Maria Auxiliadora Cannarozzo Tinoco}

Universidade Federal do Rio Grande do Sul - UFRGS

Doutoranda do Programa de Pós-Graduação em Engenharia de Produção - PPGEP

End.: Rua Cabral 983, apto. 802 - Porto Alegre - RS - CEP 90420-121

Tel.: (51) 3207-4208

E- mail: maria@producao.ufrgs.br

\section{José Luis Duarte Ribeiro, Dr.}

Universidade Federal do Rio Grande do Sul - UFRGS

Professor do Programa de Pós-Graduação em Engenharia de Produção - PPGEP

End.: Rua Luiz Manoel Gonzaga, 915, casa 2 - Porto Alegre - RS - CEP 90470-280

Tel.: (51) 3330-5501

E-mail: ribeiro@producao.ufrgs.br 